\title{
Animal models of diabetic retinopathy
}

\author{
Jose Quiroz ${ }^{1}$, Amirfarbod Yazdanyar ${ }^{2} \wedge$
}

${ }^{1}$ Medical Scientist Training Program, Albert Einstein College of Medicine, Bronx, NY, USA; ${ }^{2}$ Department of Ophthalmology and Visual Sciences, State University of New York (SUNY), Upstate Medical University, Syracuse, NY, USA

Contributions: (I) Conception and design: All authors; (II) Administrative support: All authors; (III) Provision of study materials or patients: None; (IV) Collection and assembly of data: None; (V) Data analysis and interpretation: None; (VI) Manuscript writing: All authors; (VII) Final approval of manuscript: All authors.

Correspondence to: Amirfarbod Yazdanyar, MD, PhD. Department of Ophthalmology and Visual Sciences, State University of New York (SUNY), Upstate Medical University, 550 Harrison Street, suite L, Syracuse, NY 13202, USA. Email: yazdanya@upstate.edu.

\begin{abstract}
The retina is the posterior neuro-integrated layer of the eye that conducts impulses induced by light to the optic nerve for human vision. Diseases of the retina often leads to diminished vision and in some cases blindness. Diabetes mellitus (DM) is a worldwide public health issue and globally, there is an estimated 463 million people that are affected by DM and its consequences. Diabetic retinopathy (DR) is a blinding complication of chronic uncontrolled DM and is the most common cause of blindness in the United States between the ages 24-75. It is estimated that the global prevalence of DR will increase to 191.0 million by 2030, of those 56.3 million possessing vision-threatening diabetic retinopathy (VTDR). For the most part, current treatment modalities control the complications of DR without addressing the underlying pathophysiology of the disease. Therefore, there is an unmet need for new therapeutics that not only repair the damaged retinal tissue, but also reverse the course of DR. The key element in developing these treatments is expanding our basic knowledge by studying DR pathogenesis in animal models of proliferative and non-proliferative DR (PDR and NPDR). There are numerous models available for the research of both PDR and NPDR with substantial overlap. Animal models available include those with genetic backgrounds prone to hyperglycemic states, immunologic etiologies, or environmentally induced disease. In this review we aimed to comprehensively summarize the available animal models for DR while also providing insight to each model's ocular therapeutic potential for drug discovery.
\end{abstract}

Keywords: Diabetes mellitus (DM); diabetic retinopathy (DR); animal model

Submitted Oct 04, 2020. Accepted for publication Dec 23, 2020.

doi: $10.21037 / \mathrm{atm}-20-6737$

View this article at: https://dx.doi.org/10.21037/atm-20-6737

\section{Introduction}

Diabetes mellitus (DM) is a metabolic disorder characterized by chronic hyperglycemia that increases the stress within microvasculature of many organ systems including the eye (1). Diabetic retinopathy (DR) is a major complication of DM and is the most common cause of blindness in the United States between the ages 24-75 $(2,3)$. The development of DR is directly correlated to the duration of hyperglycemia $(4,5)$, and the disease stages of DR follow a progression of blood vessel damage. Classification of DR can be established by the occurrence of neovascularization (NV). Pathological angiogenesis is the hallmark of proliferative DR (PDR) (6), and its absence indicates non-proliferative DR (NPDR) (Figure 1A-1F) $(7,8)$. NPDR begins with microangiopathy that consists of pericyte loss with endothelial cell damage, increased

$\wedge$ ORCID: 0000-0002-5393-5243. 

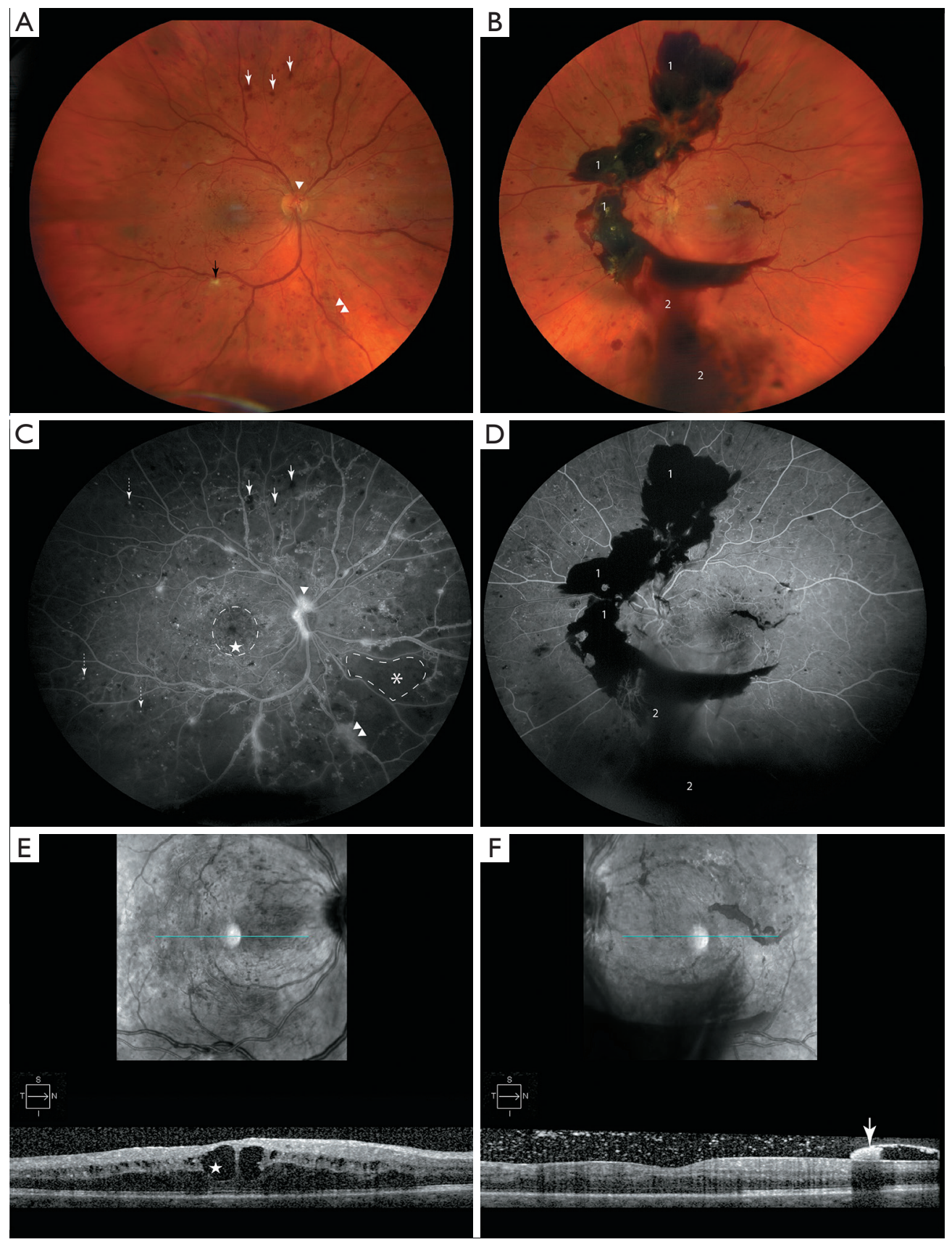

Figure 1 Features of DR. (A) Color fundus photo of the right eye of a patient with PDR, highlight pathologic changes which include ischemic damage to nerve fibers known as "cotton wool" spot (black arrow), dot-blot hemorrhages (white arrows), NVD (arrowhead) and NVE (double arrowhead). (B) The left eye of the same patient with PDR denotes advanced disease progression, highlighted are pathologic features including pre-retinal/sub-hyaloid bleeding [1] and VH [2]. (C,D) Corresponding FFA images. Pathological features shown here include MAs (dashed arrow) with corresponding features previously mentioned (A,B) and respectively denoted. Petaloid pattern of CME is encircled with dashed line. Area of capillary dropout is marked with asterix $\left(^{*}\right)$ and demarcated with dashed line. (E) OCT image of right eye shows cystoid macular edema CME that is more prominent in central macula (star). (F) OCT image of left eye. Hyper-reflective lesion (white arrow) representing pre-retinal/sub-hyoid hemorrhage. DR, diabetic retinopathy; PDR, proliferative diabetic retinopathy; NVD, neovascularization of the disc; NVE, neovascularization elsewhere; FFA, fundus fluorescein angiogram; MA, microaneurysm; VH, vitreous hemorrhage; CME, cystoid macular edema; OCT, optical coherence tomography. 
vascular permeability of the blood retinal barrier (BRB), diabetic macular edema (DME), microaneurysms (MAs), dot blot hemorrhages (DBHs) and cotton-wool spots (CWS) (Figure $1 A, 1 C, 1 E)(5,8)$. NPDR may progress to PDR, with increasing incidence with disease duration. Visionthreatening complications of untreated PDR are vitreous hemorrhage $(\mathrm{VH})$ (Figure $1 B, 1 D, 1 F$ ) and tractional retinal detachment (TRD) that require surgical intervention (8).

Epidemiologic data from 2008-2018 have shown that DR is a growing public health matter, with significant adverse impacts on patients and the health system (9). The therapeutic windows for DR lie in different stages of disease progression. A major focus of ocular therapeutics is aimed at treating DME and NV. The milestone advancement was the discovery of the clinical indications of anti-vascular endothelial growth factors (VEGF) in DR (10-12). AntiVEGF and corticosteroids have remained the mainstay treatment for many complications of DR. However, a sizeable proportion of patients ( $40 \%)$ possesses DME resistant to these mono-therapies and a small percentage remain resistant $(\sim 8 \%)$ to dual therapy leading to diminished visual outcomes (13-16). Therefore, there is an unmet need for new therapeutics to treat visionthreatening sequelae of DR and reverse the course of the disease. Animal models provide means to investigate DR and develop the next generation of ocular therapeutics. In this review, we describe current DR models and outline their benefits and shortcomings in studying different stages of DR and development of novel therapeutics.

Complex diseases such as DM with multifaceted comorbidities are influenced by numerous factors that entail genetics, environmental factors, and chemical exposures (17-23). Advancement of investigational genome-wide technology has propelled the identification of genetic variants associated with DR progression (18). These variants, along with many others, can be induced or genetically engineered in animal models. Gene editing tools such as clustered regularly interspaced short palindromic repeats (CRISPR) and targeted RNA interference (RNAi) technologies allow for precise gene modifications $(24,25)$. In addition to these major technological advancements, selectively breeding animals of desired genetic backgrounds remains as a conventional method for producing genetic animal models.

Inducible disease models can be generated with a wide variety of approaches that include diet modification, drug administration, and surgical procedures (26-29). Selection of animal species has its considerations as there is a sizeable collection to generate DR models for each stage of DR.
Animals used to model DR include rats, mice, canines, feline, swine, rabbit, non-human primates, zebra fish (23).

Of animals used to model DR, the most widely selected are rodents as they provide low cost, short life span, and quick breeding rates; indeed, mice and rats can readily be engineered to exhibit a propensity towards DR pathogenesis (23,30-35). Canines with DR phenotypes have been reported to closely model human DR. However, ethical concerns and cost efficiency impedes widespread use (23,35-40). Felines can be induced to develop DR by altering oxygenation with models generated as early as 1950s (41,42). Recently there has been a growing interest for the use of non-human primates for drug discovery in DR, although previously non-human primates have demonstrated resistance to development of PDR $(43,44)$. Zebrafish, surprisingly, have similar eye structure to humans and are growing in use for their efficient short life span and minimal cost $(35,45-48)$. Although there is a wide range of animal models to study each stage of DR, there is no single model that fully encompasses the entire DR pathogenesis of the human eye.

\section{Rodent models}

Rodent models are the most frequently utilized DR animal models. There are several methodologies available to induce various stages of DR, that range from pharmacologic induction, genetic manipulation, environmental exposures, and surgical procedures $(23,49-70)$.

Induction of pharmacologic DR is classically performed by administration of alloxan (a toxic glucose analogue) or the antibiotic streptozotocin (STZ) via destruction of the pancreas seen in type $1 \mathrm{DM}$ (T1DM). Of these two, STZ is the preferred drug for inducing DR, because of the faster rate of phenotype manifestation (52). However, animals in the STZ model rarely develop PDR.

Genetic mouse models include five main genotypes: Ins2Akita (Ins2 ${ }^{\text {Akita }}$ ), nonobese diabetic (NOD), $d b / d b$ $\left(\operatorname{Lepr}^{\mathrm{db}}\right)$, Kimba, and Akimba. Rat specific models focus around six genotypes: Zucker Diabetic Fatty (ZDF), Otsuka Long-Evans Tokushima fatty (OLETF), biobreeding (BB), Wistar Bonn/Kobori (WBN/Kob), spontaneously diabetic Torii (SDT), and Goto-Kakizaki (GK). Each genetic model varies in the mode of etiology, inheritance, pathology, and disease progression (64-66,68,70-76).

Environmental induction includes diet and oxygen exposure during early stages of life. A surgical procedure able to induce DR is pancreatectomy. Each model possesses 
careful considerations when selecting stage of disease, time to presenting phenotype, costs, and pathology limitations.

\section{Pharmacologically induced rodent models}

Dunn and McLetchie performed the first pharmacologic induction of DM in 1942 with administration of the uric acid derivative alloxan (50). The mechanism of DM induced by alloxan is by direct targeting of insulin producing $\beta$ cells of the pancreas through inhibition of the glucoseinsulin pathway enzyme, glucokinase (51). The alloxan induced PDR mouse phenotype manifests between 2-9 months after induction at the age of 8-10 weeks (77). A major limitation of alloxan is the toxic effects on the liver and kidney, although weight adjusted dosing could avoid these adverse effects. Additionally, instability of alloxan at room temperature is a notable issue, and makes handling and administration challenging (50). Due to its side effects, there has been a gradual shift toward the use of STZ.

Initial reports of STZ administration causing DM in rats and dogs date back to 1963 (52). STZ is an antibiotic that was investigated for its use as a chemotherapy and later discovered to induce hyperglycemia with characteristic symptoms of DM. Induction of DM by STZ is by targeting of pancreatic islet with the destruction of $\beta$ cells via DNA fragmentation facilitated cell death (52). $\beta$ cells take up STZ via the low affinity glucose transporter 2 (GLUT2), as STZ chemical structure closely resembles that of glucose and $\mathrm{N}$-acetyl glucosamine. As compared to alloxan, STZ shows less nephroand hepatotoxicity, and it is favored over alloxan for its ease of handling. STZ closely mimics the pathogenesis of DM with induction of hyperglycemia within 2 weeks after induction (35).

Both rats and mice readily develop diabetes with STZ treatment. Surprisingly, rats require lower doses of STZ to exhibit pathologic hyperglycemia $(23,35,69)$. STZinduced DR typically manifests after long term exposure to high glucose levels greater than $150 \mathrm{mg} / \mathrm{dL}$. Both mouse and rats with STZ DR are widely used to screen compounds for treatment of early stages of T1DM (69), and stem cell therapy (78). Mice with STZ-induced DR exhibit ganglion cell proliferation beginning 4 weeks after onset of hyperglycemia (79). At 16 weeks, the ocular phenotype resembles NPDR seen in humans, with characteristic vascular changes, and thinning of the INL and ONL $(80,81)$. Although rare, the presence of NV has also been reported (82). In rats, STZ-induced DR begins with compromised BRB structural integrity by 2 weeks of diabetes onset, followed ONL thinning at 4 weeks, NV occurring at 8 weeks, and basement membrane thickening at 1 year $(23,69,83)$. Pharmacologically induced DR models are reliable and straightforward for study designs. The limitations for pharmacologic DR rodent models are mainly related to the adverse effects of the drugs and constraint of disease progression.

\section{Diet-induced rodent models}

Diet induced diabetes in rodent models is classically conducted by high-galactose rich diets (27). C57BL/6J mice on high-fat diets ( $45 \%$ fat, $35 \%$ carbohydrate, $20 \%$ protein) have also shown propensity to develop type $2 \mathrm{DM}$ (T2DM) and provide a model to investigate diet induced DR $(27,84)$. DR phenotypes induced by high-fat diets in mice develop from a similar etiology seen in humans, where $\mathrm{DM}$ is a manifestation of high-caloric western diets. DR changes due to hyperglycemia are observed after 21 months with formation of MAs and capillary basement membrane thickening in $30 \%$ of mice $(7,27,85,86)$. Rodents with dietinduced DR are commonly used; however, they do not exhibit the exact microvascular damage seen in humans and often lack the proliferative NV (27). As a result, to achieve a good size study group with microvascular manifestations, a large starting sample size as well as extended period of hyperglycemia is required.

\section{Genetic rodent models}

Genetic factors play a vital role in the development of DR (87). The majority of rodent genetic models have well characterized genetic backgrounds and are readily manipulated with genetic tools to generate knockouts, knockdowns, and transgenic hybrids. There are five main mouse (Ins2 $2^{\text {Akita }}$, NOD, Lepr ${ }^{\mathrm{db}}$, Kimba, and Akimba) and six main rat (ZDF, OLETF, BB, WBN/Kob, SDT, and GK) specific genetic models of DR. The limitations and advantages vary greatly among genetic models. The following will briefly explain each rodent model and describe similarities in disease pathogenesis.

\section{T1DM models}

A missense mutation in insulin 2 gene causes hyperglycemia via a T1DM-like mechanism. Accumulation of misfolded insulin in $\beta$-cells defines the Ins2 ${ }^{\text {Akita }}$ mouse phenotype and leads to apoptosis $(64,66)$. The Ins $2^{\text {Akita }}$ model is typically used to study T1DM with destruction of $\beta$-cells present at 8 weeks. Retinal vascular disease is prominent for up to 
36 weeks, with increased permeability and inflammatory damage to the $\mathrm{BRB}$, marked reduction in retinal ganglion cells, and continued damage to both the inner nuclear layer (INL) and inner plexiform layer (IPL) $(23,88,89)$. Limitations of Ins2 ${ }^{\text {Akita }}$ model include its lack of similarity with the vascular changes seen in human DR. These limitations must be considered when using Ins2 ${ }^{\text {Akita }}$ model, as conclusions drawn may require additional supporting evidence to assert correlation (90). The major advantage of the Ins $2^{\text {Akita }}$ model is its utility for early progression and detection of retinal glial cell damage seen in DR, which provides a useful screening tool for treatments that involve neuroprotection (7). One such treatment involves pigment epithelium-derived factor (PEDF), hypothesized to be neuroprotective via modulation of glutamate transporter expression $(91,92)$. The Ins2 ${ }^{\text {Akita }}$ model is an ideal candidate for PEDF studies or similar treatment investigations.

An alternative to the Ins $2^{\text {Akita }}$ model is the NOD model, in which mice characteristically develop a T1DM hyperglycemia via an autoimmune response in which CD4+ and CD8+ cells target pancreatic $\beta$-cells $(23,30,65,93)$. This model was first discovered in 1974 by Yoshihiro Tochino, who initially observed a female mouse spontaneously developed hyperglycosuria $(93,94)$. Diabetes in NOD mice shows phenotypic resemblance to humans, exhibiting a polygenic etiology with numerous genetic loci correlated to T1DM phenotype (94-97). The NOD model develops $\mathrm{DM}$ at 12 weeks and retinal vasculature damage beginning with signs of apoptosis of endothelial cells and retinal glial cells. DR changes, including thickening of the retinal capillary basement membrane begin after 1 month of hyperglycemia (98). Vasoconstriction and degeneration of major blood vessels with compensatory NV manifest by 4 months of hyperglycemia $(23,57,99,100)$. Vitreal injections of pro-inflammatory cytokines (IL- $1 \beta$ and TNF- $\alpha$ ) in NOD leads to enhanced disease progression, providing a more directed model to study DR $(101,102)$. Limitations of the NOD model includes a significant gender bias where DM develops by 30 weeks in $80 \%$ of female and only $20 \%$ of male mice (30). The gender bias in the NOD model may be influenced by gender differences in gut microbiome (103). Underlying gender bias also infers major differences in polygenic background that should be a consideration in data interpretation. Nevertheless, the pathophysiology of T1DM in the NOD model closely follows that observed in humans and provides an excellent mouse model for studies. The NOD mouse model could be used to test compounds aimed at attenuating autoimmune responses or beta islet transplants (104).
Another rodent model frequently used to study T1DM is the biobreeding (BB) rat model, in which an autoimmune mediated apoptosis of pancreatic $\beta$-cells causes diabetes. A frameshift mutation found in immuneassociated nucleotide-binding protein gene ( $\operatorname{Ian} 4)$ is one genetic factor for triggering of autoimmune disease in this model. Additionally, this phenotype produces diabetes associated lymphopenia $(105,106)$. Within 1 -year BB rats typically present with pericyte dysfunction, microvascular degeneration, and MAs $(75,107)$. Gut microbiome of BB rats can contribute to the spontaneous T1DM phenotype (108). Further investigation of the exact mechanism of spontaneous T1DM poses a potential limitation of the BB rat model. However, the BB rat model still provides a strong T1DM phenotype for investigations.

\section{T2DM models}

The obesity epidemic in the United States has driven the need for research animal models $(109,110)$. T2DM is frequently associated with obesity (111). Two commonly used obesity rodent models include the ZDF rat model and the Lepr $^{\mathrm{db}}$ mouse model that hold mutations in the leptin receptor gene leading to obesity and hyperglycemia $(33,112,113)$.

ZDF rats display a reduction in leptin receptor expression that promotes obesity and serve as an excellent model for research of associated metabolic abnormalities (114). However, these rats may not be an ideal DR model, as retinal vascular damage is often absent even up to 42 weeks of chronic hyperglycemia (114).

Lepr $^{\mathrm{db}}$ mice carry a mutation in the leptin receptor that results in defective leptin signaling. Homozygous animals become insensitive to leptin, leading to development of obesity and chronic hyperglycemia within the first 2 months of age $(112,115)$. The pathophysiology of diabetes in Lepr ${ }^{\mathrm{db}}$ mouse model closely mimics that seen in T2DM, with late stages leading to atrophy of pancreatic $\beta$ cells and dependence on exogenous insulin $(112,115)$. In the retina of Lepr $^{\mathrm{db}}$ mice, damage to retinal glia cells and increased central retinal membrane thickness is detected after 6 weeks of hyperglycemia $(110,116)$. Characteristics of Lepr ${ }^{\mathrm{db}}$ mouse include thinning of the ONL seen by 8 weeks and thinning of the INL by 14 weeks of hyperglycemia $(116,117)$. Acellular capillaries and retinal NV present by 18 weeks (118). Limitations of the Lepr ${ }^{\mathrm{db}}$ mouse model are related to the rapid continuation of severe disease with increasing blood sugar levels and worsening of cardiovascular disease that shortens lifespan to about 10 months $(119,120)$. The primary advantage of the Lepr ${ }^{\mathrm{db}}$ 
mouse is it provides an exceptional model for screening of late stage DR treatments designed to alleviate the DR symptoms of reactive gliosis and severe vascular damage.

The OLETF rat model spontaneously develops T2DM via a mutation in G-protein-coupled receptor 10 (GPR10) that leads to obesity $(72,73)$. Onset of diabetes is present by 6 months, with abrupt increases in blood glucose (73). Microvasculature changes manifest approximately 6 weeks following diabetes onset with inflammation throughout retinal microcirculation (34). Vascular leakage is noted by 3 months of hyperglycemia, due to damaged endothelial cells and pericyte loss $(121,122)$. Limitations of this model are delayed onset diabetes and absence of a common feature of DR pathology, acellular capillaries.

Another rodent model for studying T2DM is the WBN/ Kob rat model that spontaneously develops hyperglycemia via an unknown mechanism regulated by sex hormones $(7,123)$. The causal genes have not been elucidated, but reports suggest regions of significance on chromosome 7 in WBN/Kob locus 1 (pdwk1) $(124,125)$. Retinal disease in this model is marked by intraretinal angiopathy consisting of $\mathrm{NV}$ and hyalinization. Although the genotype is unknown, the phenotype elicited is this model still provides a viable research model for understanding DR progression.

Additional rat models are those that develop nonobese T2DM, the SDT and the GK models. Insulin insensitivity is the primary mechanism by which T2DM develops, with atrophy of pancreatic $\beta$-cells in late disease. Out of these two rat models, the SDT rat more closely resembles the pathophysiology seen in humans. The genes associated with the SDT model are correlated to three primary genes: Gisdt1, Gisdt2, and Gisdt3, on chromosome 1, 2 and X, respectively; all are related to glucose intolerance $(76,126,127)$. SDT rats develop glycosuria between 20-45 weeks depending on gender (126). Diabetes manifests in male rats by 40 weeks with complete conversion at 65 weeks; however, only $33 \%$ of female rats go on to develop disease (126).

SDT rats exhibit retinal disease that features NV without underlying ischemia, as well as apoptosis in both the ganglion cell layer (GCL) and the INL of the retina. Other ocular features of SDT rat include retinal detachment and fibrous remodeling (128), and large retinal folds with extensive vascular leakage surrounds the optic disk, which closely resembles human disease (129-131). A transgenic hybrid, SDT(fa), generated by introduction of the fatty ( $f a)$ allele from the ZDF rat model into SDT rats, displays a more rapid onset of DR (132). One limitation of the SDT model is the lack of MA or NV; therefore, the SDT model is better suited for NPDR research. Similar to the Ins2 $2^{\text {Akita }}$ mouse model, SDT model possess a prominent gender bias in onset of disease that is a major consideration for study designs. The major benefit of the SDT rat model is the development of TRD in the late stages of DR.

The GK rat model develops diabetes earlier than SDT model with presentation of hyperglycemia within 4 weeks and DM by 6 weeks $(133,134)$. There is a polygenic background contributing to the GK disease phenotype with reports of 192 potential genes (135). Disease manifestations of GK are defined by reduced retinal blood flow with absence of diameter variation of veins and arteries $(7,134)$. The GK rat model exhibits microcirculatory changes in the retina and loss of pericytes that leads to BRB permeability increase at 3 months following disease onset. This is a good model to study circulatory changes in DR, but it does not show a clear genotype-to-phenotype linkage.

\section{Non-diabetic/hybrid pathology models}

Several genetic murine models have been developed with the aim of generating models physiologically similar to human retinal disease. An example is the non-diabetic Kimba mouse, that is genetically modified to overexpress retinal VEGF; driven by mutations at the rhodopsin promoter loci $(67,136)$. The Kimba mouse model manifests retinal disease within the first week of life with markedly reduced ONL and INL. Abnormalities of retinal microvascular are noted by 1 month and pericyte loss by 2 months (136). An additional mouse line, Akimba, was generated by cross breeding Ins2 ${ }^{\text {Akita }}$ mice and Kimba mice (68). The hybrid Akimba mouse, as expected, possesses characteristics from both parental strains that includes hyperglycemia with significant edema and NV (68). A limitation of the Kimba mouse model is early disease development and rapid progression that is present at birth and is focused on the late stage of disease without hyperglycemic etiology. The research benefits of Kimba mice are that DR pathogenesis is controlled by VEGF production, providing an efficient model for treatment development and research focused on NV. Akimba mice are an excellent model for DR research with few limitations common to all animal models. The characteristics from the parental strains are additive and as a result significantly bias retinal disease progression (68).

\section{Environmental exposure rodent models}

\section{Oxygen-induced retinopathy (OIR)}

Anomalous NV in the posterior segment of the eye is the 
hallmark of late stage DR and the distinguishing feature of PDR from NPDR $(8,23)$. The pathogenesis of PDR is driven by chronic hyperglycemia that ultimately leads to vascular damage, and subsequent retinal ischemia that promotes NV. Cycling of hyperoxia and hypoxia produces OIR that physiologically mimics ischemic events and induce compensatory NV. Rodent models of OIR are used to study vascular changes in retinal diseases such as DR (137-139). In OIR models, after exposure to cycling hyperoxia, rodents exhibit two phases of vascular retinal disease. Initially, vasculature regresses in hyperoxic conditions; ensuing ischemia leads to compensatory hypoxiainduced NV $(59,137)$. This hypoxia results in release of angiogenic factors such as VEGF that stimulate angiogenesis in avascular areas to reproduce DR vascular disease $(58,140)$.

\section{Mouse OIR model}

The mouse OIR model was first reported by Smith et al. in 1994 (58). Commonly used to model retinopathy of prematurity (ROP) but pathologically includes similar features of DR. In it, OIR is generated by exposing neonatal mice to an environment of $75 \%$ oxygen at 7 days of age for a duration of at least 5 days, followed by a return to room air for 5 days. The retinopathy begins under hyperoxia with regression of retinal blood vessels from the central zone resulting in vaso-obliteration (138). Exposure to normoxic conditions leads to ischemia and release of hypoxic-inducible factors, such as erythropoietin and VEGF that trigger angiogenesis $(58,60,140)$. Gradual vascularization of the vaso-obliterated areas mimics human proliferative retinopathies such as DR and $\operatorname{ROP}(58,141)$. Disease features of the OIR mouse model include reduction in INL and IPL thickness and degeneration of BRB with increased vascular leakage. New blood vessels are formed distinctly and termed "endothelial tufts" that may protrude into the vitreous $(58,141)$. The OIR mouse model provides an excellent example to study PDR, because the pathologic angiogenesis resembles human disease. Studies using the OIR mouse model demonstrate that the inhibition of VEGF signaling via soluble VEGF receptor 1 antibody reduces pathologic retinal NV (63). Major limitation of this model are the absence of chronic hyperglycemia, thus limiting the studies to microvasculature changes seen in PDR and retinal NV which is transient and spontaneously regress, unlike PDR.

\section{Canine DR models}

Surgical procedures were the primary method used to induce diabetes in early animal models. Historically insulin was first isolated from pancreas of canines for treatment of "Juvenile Diabetes" (49), an immune mediated T1DM. Canines develop diabetes shortly after pancreatectomy and provided one of the earliest animal models to study diabetes $(7,29)$. In addition to pancreatectomy, other methodologies used to generate canine DR models include high-galactose diet induction, alloxan/STZ administration, and growth hormone regimens (7). Canines on long-term high galactose diets develop DR, with severe stages of disease manifesting by 5 years $(37,142,143)$. Morphology of DR in canines closely resembles disease seen in humans (144), and includes many of the classical features such as MAs, pericyte loss, thickened capillary basement membrane, and dot and blot hemorrhages (145). Pathologic vascularization is often absent, limiting this model to NPDR studies. The high cost of canine care and the ethical unpopularity of using canines in research have impeded the use of canine models for DR research studies.

\section{Feline models}

Felines can develop DM and display the same pathological characteristics as human T1DM and T2DM $(144,146)$. Pancreatectomy is often used to induce glucose intolerance. However, the time to feline DR phenotype ranges from 5 to 9 years of chronic hyperglycemia $(146,147)$. Felines can display retinal changes including CWS, vascular leakage, and NV $(147,148)$. MAs in felines have been reported in some studies and absent in others (148). Alloxan and STZ are also effective modalities in developing DR in felines and often used as complements to partial pancreatectomy (149). The feline OIR model was first described in the 1950s, as one of the earliest models exploring the effects of oxygen concentration on retinal disease (41). Similar to the rodent OIR model, kittens were exposed to hyperoxic conditions ( $80 \%$ oxygen) for $4-5$ days, which induced retinal vessel regression and vaso-obliteration. When kittens are returned to room air (21\% oxygen), hypoxiainduced angiogenesis develops $(41,42)$. The feline OIR model exhibits similar disease features to mouse OIR model. However, felines do not display retinal detachment. There are multiple limitations with using feline models, including long incubations required for DR development and unavailability of research reagents. These limitations make this model difficult to use. However, felines exhibit a moderate resistance to DR and may offer a novel platform to investigate severe stages of disease in future studies. 


\section{Swine models}

Swines have found utility in many disciplines of disease research. The human eye and the swine eye share similarity in size, retinal structure, and vasculature; these are appealing characteristics for modeling DR (150). The majority of swine eye research is not performed with in vivo models, but rather using in vitro experiments with swine retinal cells, specifically Müller cells $(151,152)$. Swine in vivo DR models can be pharmacologically induced by administration of alloxan or STZ (151), and biologically induced with intravitreal injections of retinal pigment epithelial (RPE) cells (153). Alloxan-induced DR in swine exhibit retinal basement membrane thickening, pericyte destruction, and vascular edema within 4-6 months of hyperglycemia (154). Transgenic swine models also demonstrate signs of DR. Swine carrying a mutated human $H N F-1 \alpha$ (P291fsinsC) developed chronic hyperglycemia ( $>200 \mathrm{mg} / \mathrm{dL}$ ) by 1 month of age. NPDR features such as retinal hemorrhage and CWS were detected by 4 months of hyperglycemia, yet PDR was not observed in this model. This limited study requires further investigation (155). Development of swine DR models may provide an excellent means for therapeutic development that may overshadow the cost limitations and scarcity of research reagents.

\section{Rabbit models}

Rabbit models of DR have been generated by pharmacologic agents, altered diet, or direct implantations of VEGF (inherently non-diabetic) into the retina. Each has its own drawbacks. Pharmacologic induction is the most common method to induce DR in rabbits. Typical agent use is STZ $(100 \mathrm{mg} / \mathrm{kg})$, which abruptly increases blood glucose levels (>200 mg/dL) (156). DR lesions present with variable distribution within 5 months of STZ administration. Approximately $50 \%$ of rabbits develop PDR. Interestingly, $40 \%$ only show MAs, DBH, and thrombosis. The remaining $10 \%$ exhibit only hard exudates and moderate microangiopathy $(35,156)$.

Diet-induced DR in rabbits is achieved with highcaloric-hyperlipidemic diet (157). However, minimal DR development and long incubation time make this approach less attractive.

Direct implantation of VEGF is a viable method to induce DR changes in rabbits (158-160). Rabbits develop PDR with NV within 3 weeks of VEGF polymeric implant (160). However, regression of NV occurs 5 weeks after implantation leaving a short window for study. The use of human recombinant basic fibroblast growth factor (bFGF) in a polymeric implant yields more efficient DR development within 1-2 weeks of implantations and DR features are hemorrhage, NV, and TRD (158).

The rabbit model provides an excellent means to screen therapeutic compounds, as the DR phenotype can be achieved in a short time, and the resultant retinal pathology is similar to human disease. The limitations of this model are high cost and variation of DR among rabbit species (159).

\section{Non-human primate models}

DM may be elicited in non-human primates by chemical or surgical induction $(44,161,162)$. Despite the presence of long-term hyperglycemia in these models, non-human primates are particularly resistant to PDR (44). After administration of Alloxan or STZ, a long duration of hyperglycemia is required before early sings of DR are detected $(44,161)$. This resilience suggests that non-human primates possess means to minimize the effects of widely uncontrolled chronic hyperglycemia.

Cynomolgus macaque or obese rhesus monkeys display spontaneous T2DM, with retinal ischemia, MAs, CWS, intra-retinal hemorrhages and hard exudates in the macula without NV $(43,161)$. One of the major limitations of nonhuman primates for drug discovery is the long housing duration before DR develops (43). Due to lack of NV, nonhuman primates are limited to NPDR studies (7). The major benefit that non-human primate models provide is the presence of a macula that is not found in other animal models. Future directions for developing DR models of non-human primate require a better understanding of biological mechanisms that play a role in NV during chronic hyperglycemia.

\section{Zebrafish models}

A unique DR animal model that surprisingly shares similar eye structure to the human eye is zebrafish. DR can be generated in adult zebrafish with hypoxia induction $(163,164)$. Transgenic fluorescent zebrafish $\mathrm{Tg}(\mathrm{fli1}$ :EGFP)y that are exposed to hypoxic conditions with $\sim 10 \%$ air for 12 days develop new blood vessels that are readily identifiable with GFP imaging (165). Genetic mutation of the von HippelLindau tumor suppressor gene (vbl1) also results in a DR-like angiogenesis (166). Zebrafish carrying this vhl1 mutation have pronounced retinal vascular formation and upregulation 
of VEGF. DR features in this model include increased number of hyaloid vasculatures with simultaneous vascular leakage, retinal edema, severe $\mathrm{NV}$ and ensuing retinal detachment (166). A major advantage of using zebrafish is its ease of genetic manipulation, in addition to its low cost and quick breeding rate. Zebrafish serve as a viable DR model that requires further characterization and can expedite empiric drug screenings exponentially (45).

\section{Conclusions}

The prevalence of diabetes and its complications continue to remain a major public health concern in the United States. The utilization of animal models serves a vital role by furthering the understanding of DR pathophysiology, progression, and etiology. Future advancement of DR animal models is required as DR is a multifaceted disease including vascular and neurologic components that are influenced by both genetics and environmental exposures. While no single animal model encompassing the entire DR pathogenesis exists, we find promise in furthering comprehension of genetic models and development of new high-order animal models. To this end, development of ocular therapeutics for DR treatments holds a favorable future.

\section{Acknowledgments}

Funding: This work was supported by an unrestricted Grant from Research to Prevent Blindness (RPB) to the Department of Ophthalmology \& Visual Sciences; startup funding from the Department of Ophthalmology \& Visual Sciences and the College of Medicine.EY026556 (AY) and NIGMS MSTP Training Grant T32GM007288 (JQ).

\section{Footnote}

Provenance and Peer Review: This article was commissioned by the Guest Editor (Susanna S. Park) for the series "Novel Tools and Therapies for Ocular Regeneration" published in Annals of Translational Medicine. The article has undergone external peer review.

Peer Review File: Available at https://dx.doi.org/10.21037/ atm-20-6737

Conflicts of Interest: Both authors have completed the ICMJE uniform disclosure form (available at https://dx.doi. org/10.21037/atm-20-6737). The series "Novel Tools and Therapies for Ocular Regeneration" was commissioned by the editorial office without any funding or sponsorship. The authors have no other conflicts of interest to declare.

Ethical Statement: The authors are accountable for all aspects of the work in ensuring that questions related to the accuracy or integrity of any part of the work are appropriately investigated and resolved.

Open Access Statement: This is an Open Access article distributed in accordance with the Creative Commons Attribution-NonCommercial-NoDerivs 4.0 International License (CC BY-NC-ND 4.0), which permits the noncommercial replication and distribution of the article with the strict proviso that no changes or edits are made and the original work is properly cited (including links to both the formal publication through the relevant DOI and the license). See: https://creativecommons.org/licenses/by-nc-nd/4.0/.

\section{References}

1. Guthrie RA, Guthrie DW. Pathophysiology of diabetes mellitus. Crit Care Nurs Q 2004;27:113-25.

2. Klein BE. Overview of epidemiologic studies of diabetic retinopathy. Ophthalmic Epidemiol 2007;14:179-83.

3. Lee R, Wong TY, Sabanayagam C. Epidemiology of diabetic retinopathy, diabetic macular edema and related vision loss. Eye Vis (Lond) 2015;2:17.

4. Nentwich MM, Ulbig MW. Diabetic retinopathy - ocular complications of diabetes mellitus. World J Diabetes 2015;6:489-99.

5. Cunha-Vaz J. Characterization and relevance of different diabetic retinopathy phenotypes. Dev Ophthalmol 2007;39:13-30.

6. Liu CH, Wang Z, Sun Y, et al. Animal models of ocular angiogenesis: from development to pathologies. Faseb J 2017;31:4665-81.

7. Robinson R, Barathi VA, Chaurasia SS, et al. Update on animal models of diabetic retinopathy: from molecular approaches to mice and higher mammals. Dis Model Mech 2012;5:444-56.

8. Cheung N, Mitchell P, Wong TY. Diabetic retinopathy. Lancet 2010;376:124-36.

9. Cheloni R, Gandolfi SA, Signorelli C, et al. Global prevalence of diabetic retinopathy: protocol for a systematic review and meta-analysis. BMJ Open 2019;9:e022188. 
10. Chen E, Park CH. Use of intravitreal bevacizumab as a preoperative adjunct for tractional retinal detachment repair in severe proliferative diabetic retinopathy. Retina 2006;26:699-700.

11. Oshima Y, Sakaguchi H, Gomi F, et al. Regression of iris neovascularization after intravitreal injection of bevacizumab in patients with proliferative diabetic retinopathy. Am J Ophthalmol 2006;142:155-8.

12. Chen HX, Gore-Langton RE, Cheson BD. Clinical trials referral resource: Current clinical trials of the anti-VEGF monoclonal antibody bevacizumab. Oncology (Williston Park) 2001;15:1017, 1020, 1023-6.

13. Lois N, McCarter RV, O’Neill C, et al. Endothelial progenitor cells in diabetic retinopathy. Front Endocrinol (Lausanne) 2014;5:44.

14. Simó R, Hernández C. Novel approaches for treating diabetic retinopathy based on recent pathogenic evidence. Prog Retin Eye Res 2015;48:160-80.

15. Choi MY, Jee D, Kwon JW. Characteristics of diabetic macular edema patients refractory to anti-VEGF treatments and a dexamethasone implant. PLoS One 2019:14:e0222364.

16. Pacella F, Romano MR, Turchetti P, et al. An eighteenmonth follow-up study on the effects of Intravitreal Dexamethasone Implant in diabetic macular edema refractory to anti-VEGF therapy. Int J Ophthalmol 2016;9:1427-32.

17. Simó-Servat O, Hernández C, Simó R. Diabetic retinopathy in the context of patients with diabetes. Ophthalmic Res 2019;62:211-7.

18. Cabrera AP, Mankad RN, Marek L, et al. Genotypes and phenotypes: a search for influential genes in diabetic retinopathy. Int J Mol Sci 2020;21:2712.

19. Pang H, Luo S, Huang G, et al. Advances in knowledge of candidate genes acting at the beta-cell level in the pathogenesis of T1DM. Front Endocrinol (Lausanne) 2020;11:119.

20. Schulz M, Romppel M, Grande G. Built environment and health: a systematic review of studies in Germany. J Public Health (Oxf) 2018;40:8-15.

21. Feng J, Glass TA, Curriero FC, et al. The built environment and obesity: a systematic review of the epidemiologic evidence. Health Place 2010;16:175-90.

22. Gary-Webb TL, Suglia SF, Tehranifar P. Social epidemiology of diabetes and associated conditions. Curr Diab Rep 2013;13:850-9.

23. Olivares AM, Althoff K, Chen GF, et al. Animal models of diabetic retinopathy. Curr Diab Rep 2017;17:93.
24. Hsu PD, Lander ES, Zhang F. Development and applications of CRISPR-Cas9 for genome engineering. Cell 2014;157:1262-78.

25. Sledz CA, Williams BR. RNA interference in biology and disease. Blood 2005;106:787-94.

26. Patel DD, Lipinski DM. Validating a low-cost laser speckle contrast imaging system as a quantitative tool for assessing retinal vascular function. Sci Rep 2020;10:7177.

27. Preguiça I, Alves A, Nunes S, et al. Diet-induced rodent models of diabetic peripheral neuropathy, retinopathy and nephropathy. Nutrients 2020;12:250.

28. Nakagami Y, Hatano E, Chayama Y, et al. An antiPLVAP antibody suppresses laser-induced choroidal neovascularization in monkeys. Eur J Pharmacol 2019;854:240-6.

29. Kumar S, Singh R, Vasudeva N, et al. Acute and chronic animal models for the evaluation of anti-diabetic agents. Cardiovasc Diabetol 2012;11:9.

30. Makino S, Kunimoto K, Muraoka Y, et al. Breeding of a non-obese, diabetic strain of mice. Jikken Dobutsu 1980;29:1-13.

31. Thayer TC, Wilson SB, Mathews CE. Use of nonobese diabetic mice to understand human type 1 diabetes. Endocrinol Metab Clin North Am 2010;39:541-61.

32. Pearson JA, Wong FS, Wen L. The importance of the Non Obese Diabetic (NOD) mouse model in autoimmune diabetes. J Autoimmun 2016;66:76-88.

33. Hummel KP, Dickie MM, Coleman DL. Diabetes, a new mutation in the mouse. Science 1966;153:1127-8.

34. Miyamoto K, Hiroshiba N, Tsujikawa A, et al. In vivo demonstration of increased leukocyte entrapment in retinal microcirculation of diabetic rats. Invest Ophthalmol Vis Sci 1998;39:2190-4.

35. Lai AK, Lo AC. Animal models of diabetic retinopathy: summary and comparison. J Diabetes Res 2013;2013:106594.

36. Engerman RL, Bloodworth JM Jr. Experimental diabetic retinopathy in dogs. Arch Ophthalmol 1965;73:205-10.

37. Kobayashi T, Kubo E, Takahashi Y, et al. Retinal vessel changes in galactose-fed dogs. Arch Ophthalmol 1998;116:785-9.

38. Kador PF, Takahashi Y, Wyman M, et al. Diabeteslike proliferative retinal changes in galactose-fed dogs. Arch Ophthalmol 1995;113:352-4.

39. Miller EJ, Brines CM. Canine diabetes mellitus associated ocular disease. Top Companion Anim Med 2018;33:29-34.

40. McLeod DS, Brownstein R, Lutty GA. Vaso-obliteration in the canine model of oxygen-induced retinopathy. Invest 
Ophthalmol Vis Sci 1996;37:300-11.

41. Ashton N, Ward B, Serpell G. Effect of oxygen on developing retinal vessels with particular reference to the problem of retrolental fibroplasia. Br J Ophthalmol 1954;38:397-432.

42. Phelps DL, Rosenbaum AL. Effects of marginal hypoxemia on recovery from oxygen-induced retinopathy in the kitten model. Pediatrics 1984;73:1-6.

43. Shimazawa M, Hara H. Establishment of retinal disease models using non-human primates and its strategy for drug discovery. Nihon Yakurigaku Zasshi 2018;152:139-46.

44. Tso MO, Kurosawa A, Benhamou E, et al.

Microangiopathic retinopathy in experimental diabetic monkeys. Trans Am Ophthalmol Soc 1988;86:389-421.

45. Jo DH, Cho CS, Kim JH, et al. Animal models of diabetic retinopathy: doors to investigate pathogenesis and potential therapeutics. J Biomed Sci 2013;20:38.

46. Goldsmith JR, Jobin C. Think small: zebrafish as a model system of human pathology. J Biomed Biotechnol 2012;2012:817341.

47. Coomer CE, Morris AC. Capn5 expression in the healthy and regenerating zebrafish retina. Invest Ophthalmol Vis Sci 2018;59:3643-54.

48. Ali Z, Zang J, Lagali N, et al. Photoreceptor degeneration accompanies vascular changes in a zebrafish model of diabetic retinopathy. Invest Ophthalmol Vis Sci 2020:61:43.

49. Banting FG, Best CH. The internal secretion of the pancreas. 1922. Indian J Med Res 2007;125:251-66.

50. McLetchie NG. Alloxan diabetes: a discovery, albeit a minor one. J R Coll Physicians Edinb 2002;32:134-42.

51. Dixon KC, King AJ, Malinin T. Protein in dying beta-cells of the pancreatic islets. Q J Exp Physiol Cogn Med Sci 1960;45:202-12.

52. Rakieten N, Rakieten ML, Nadkarni MV. Studies on the diabetogenic action of streptozotocin (NSC-37917). Cancer Chemother Rep 1963;29:91-8.

53. Eleazu CO, Eleazu KC, Chukwuma S, et al. Review of the mechanism of cell death resulting from streptozotocin challenge in experimental animals, its practical use and potential risk to humans. J Diabetes Metab Disord 2013:12:60.

54. Engerman RL, Kern TS. Experimental galactosemia produces diabetic-like retinopathy. Diabetes 1984;33:97-100.

55. Joussen AM, Doehmen S, Le ML, et al. TNF-alpha mediated apoptosis plays an important role in the development of early diabetic retinopathy and long-term histopathological alterations. Mol Vis 2009;15:1418-28.
56. Stone J, Itin A, Alon T, et al. Development of retinal vasculature is mediated by hypoxia-induced vascular endothelial growth factor (VEGF) expression by neuroglia. J Neurosci 1995;15:4738-47.

57. Grossniklaus HE, Kang SJ, Berglin L. Animal models of choroidal and retinal neovascularization. Prog Retin Eye Res 2010;29:500-19.

58. Smith LE, Wesolowski E, McLellan A, et al. Oxygeninduced retinopathy in the mouse. Invest Ophthalmol Vis Sci 1994;35:101-11.

59. Lange C, Ehlken C, Stahl A, et al. Kinetics of retinal vasoobliteration and neovascularisation in the oxygen-induced retinopathy (OIR) mouse model. Graefes Arch Clin Exp Ophthalmol 2009;247:1205-11.

60. Pierce EA, Avery RL, Foley ED, et al. Vascular endothelial growth factor/vascular permeability factor expression in a mouse model of retinal neovascularization. Proc Natl Acad Sci U S A 1995;92:905-9.

61. Chen J, Connor KM, Aderman CM, et al. Suppression of retinal neovascularization by erythropoietin siRNA in a mouse model of proliferative retinopathy. Invest Ophthalmol Vis Sci 2009;50:1329-35.

62. Connor KM, Krah NM, Dennison RJ, et al. Quantification of oxygen-induced retinopathy in the mouse: a model of vessel loss, vessel regrowth and pathological angiogenesis. Nat Protoc 2009;4:1565-73.

63. Aiello LP, Pierce EA, Foley ED, et al. Suppression of retinal neovascularization in vivo by inhibition of vascular endothelial growth factor (VEGF) using soluble VEGFreceptor chimeric proteins. Proc Natl Acad Sci U S A 1995;92:10457-61.

64. Izumi T, Yokota-Hashimoto H, Zhao S, et al. Dominant negative pathogenesis by mutant proinsulin in the Akita diabetic mouse. Diabetes 2003;52:409-16.

65. Serreze DV, Chapman HD, Varnum DS, et al. Initiation of autoimmune diabetes in NOD/Lt mice is MHC class I-dependent. J Immunol 1997;158:3978-86.

66. Wang J, Takeuchi T, Tanaka S, et al. A mutation in the insulin 2 gene induces diabetes with severe pancreatic beta-cell dysfunction in the Mody mouse. J Clin Invest 1999;103:27-37.

67. Okamoto N, Tobe T, Hackett SF, et al. Transgenic mice with increased expression of vascular endothelial growth factor in the retina: a new model of intraretinal and subretinal neovascularization. Am J Pathol 1997;151:281-91.

68. Rakoczy EP, Ali Rahman IS, Binz N, et al. Characterization of a mouse model of hyperglycemia and 
retinal neovascularization. Am J Pathol 2010;177:2659-70.

69. Furman BL. Streptozotocin-induced diabetic models in mice and rats. Curr Protoc Pharmacol 2015;70:5.47.15.47.20.

70. Schmidt RE, Dorsey DA, Beaudet LN, et al. Analysis of the Zucker Diabetic Fatty (ZDF) type 2 diabetic rat model suggests a neurotrophic role for insulin/IGF-I in diabetic autonomic neuropathy. Am J Pathol 2003;163:21-8.

71. Yokoi N, Hoshino M, Hidaka S, et al. A novel rat model of type 2 diabetes: the Zucker fatty diabetes mellitus ZFDM rat. J Diabetes Res 2013;2013:103731.

72. Watanabe TK, Suzuki M, Yamasaki Y, et al. Mutated G-protein-coupled receptor GPR10 is responsible for the hyperphagia/dyslipidaemia/obesity locus of Dmo1 in the OLETF rat. Clin Exp Pharmacol Physiol 2005;32:355-66.

73. Lu ZY, Bhutto IA, Amemiya T. Retinal changes in Otsuka long-evans Tokushima Fatty rats (spontaneously diabetic rat)--possibility of a new experimental model for diabetic retinopathy. Jpn J Ophthalmol 2003;47:28-35.

74. Miyamura N, Amemiya T. Lens and retinal changes in the WBN/Kob rat (spontaneously diabetic strain). Electronmicroscopic study. Ophthalmic Res 1998;30:221-32.

75. Sima AA, Chakrabarti S, Garcia-Salinas R, et al. The BBrat--an authentic model of human diabetic retinopathy. Curr Eye Res 1985;4:1087-92.

76. Yamada H, Yamada E, Higuchi A, et al. Retinal neovascularisation without ischaemia in the spontaneously diabetic Torii rat. Diabetologia 2005;48:1663-68.

77. Schröder S, Palinski W, Schmid-Schönbein GW. Activated monocytes and granulocytes, capillary nonperfusion, and neovascularization in diabetic retinopathy. Am J Pathol 1991;139:81-100.

78. Yazdanyar A, Zhang P, Dolf C, et al. Effects of intravitreal injection of human CD34+ bone marrow stem cells in a murine model of diabetic retinopathy. Exp Eye Res 2020;190:107865.

79. Kumar S, Zhuo L. Longitudinal in vivo imaging of retinal gliosis in a diabetic mouse model. Exp Eye Res 2010;91:530-6.

80. Martin PM, Roon P, van Ells TK, et al. Death of retinal neurons in streptozotocin-induced diabetic mice. Invest Ophthalmol Vis Sci 2004;45:3330-6.

81. Feit-Leichman RA, Kinouchi R, Takeda M, et al. Vascular damage in a mouse model of diabetic retinopathy: relation to neuronal and glial changes. Invest Ophthalmol Vis Sci 2005;46:4281-7.

82. Su L, Ji J, Bian J, et al. Tacrolimus (FK506) prevents early retinal neovascularization in streptozotocin-induced diabetic mice. Int Immunopharmacol 2012;14:606-12.

83. Zhang J, Wu Y, Jin Y, et al. Intravitreal injection of erythropoietin protects both retinal vascular and neuronal cells in early diabetes. Invest Ophthalmol Vis Sci 2008;49:732-42.

84. Surwit RS, Kuhn CM, Cochrane C, et al. Dietinduced type II diabetes in C57BL/6J mice. Diabetes 1988;37:1163-7.

85. Joussen AM, Poulaki V, Le ML, et al. A central role for inflammation in the pathogenesis of diabetic retinopathy. Faseb J 2004;18:1450-52.

86. Robison WG Jr, Jacot JL, Glover JP, et al. Diabeticlike retinopathy: early and late intervention therapies in galactose-fed rats. Invest Ophthalmol Vis Sci 1998;39:1933-41.

87. Simó-Servat O, Hernández C, Simó R. Genetics in diabetic retinopathy: current concepts and new insights. Curr Genomics 2013;14:289-99.

88. Barber AJ, Antonetti DA, Kern TS, et al. The Ins2Akita mouse as a model of early retinal complications in diabetes. Invest Ophthalmol Vis Sci 2005:46:2210-8.

89. Han Z, Guo J, Conley SM, et al. Retinal angiogenesis in the Ins2(Akita) mouse model of diabetic retinopathy. Invest Ophthalmol Vis Sci 2013;54:574-84.

90. McLenachan S, Chen X, McMenamin PG, et al. Absence of clinical correlates of diabetic retinopathy in the Ins2Akita retina. Clin Exp Ophthalmol 2013;41:582-92.

91. Shen X, Zhong Y, Xie B, et al. Pigment epithelium derived factor as an anti-inflammatory factor against decrease of glutamine synthetase expression in retinal Müller cells under high glucose conditions. Graefes Arch Clin Exp Ophthalmol 2010;248:1127-36.

92. Xie B, Jiao Q, Cheng Y, et al. Effect of pigment epithelium-derived factor on glutamate uptake in retinal Muller cells under high-glucose conditions. Invest Ophthalmol Vis Sci 2012;53:1023-32.

93. Johansen K. The spectrum of plasma insulin responses in middle-aged and old non-obese diabetics with various degrees of metabolic derangement. Acta Med Scand 1973;194:157-64.

94. Hanafusa T, Miyagawa J, Nakajima H, et al. The NOD mouse. Diabetes Res Clin Pract 1994;24 Suppl:S307-11.

95. Baxter AG, Cooke A. The genetics of the NOD mouse. Diabetes Metab Rev 1995;11:315-35.

96. Leiter EH, Prochazka M, Coleman DL. The non-obese diabetic (NOD) mouse. Am J Pathol 1987;128:380-3.

97. Simpson PB, Mistry MS, Maki RA, et al. Cuttine edge: diabetes-associated quantitative trait locus, 
$\mathrm{Idd} 4$, is responsible for the $\mathrm{IL}-12 \mathrm{p} 40$ overexpression defect in nonobese diabetic (NOD) mice. J Immunol 2003;171:3333-7.

98. Li CR, Sun SG. VEGF expression and cell apoptosis in NOD mouse retina. Int J Ophthalmol 2010;3:224-7.

99. Shaw SG, Boden JP, Biecker E, et al. Endothelin antagonism prevents diabetic retinopathy in NOD mice: a potential role of the angiogenic factor adrenomedullin. Exp Biol Med (Maywood) 2006;231:1101-5.

100.Lee S, Harris NR. Losartan and ozagrel reverse retinal arteriolar constriction in non-obese diabetic mice. Microcirculation 2008;15:379-87.

101. Mugisho OO, Rupenthal ID, Squirrell DM, et al. Intravitreal pro-inflammatory cytokines in non-obese diabetic mice: modelling signs of diabetic retinopathy. PLoS One 2018;13:e0202156.

102.Mugisho OO, Green CR, Squirrell DM, et al. Connexin43 hemichannel block protects against the development of diabetic retinopathy signs in a mouse model of the disease. J Mol Med (Berl) 2019;97:215-29.

103. Yurkovetskiy L, Burrows M, Khan AA, et al. Gender bias in autoimmunity is influenced by microbiota. Immunity 2013;39:400-12.

104. Niclauss N, Meier R, Bédat B, et al. Beta-cell replacement: pancreas and islet cell transplantation. Endocr Dev 2016;31:146-62.

105. MacMurray AJ, Moralejo DH, Kwitek AE, et al. Lymphopenia in the $\mathrm{BB}$ rat model of type 1 diabetes is due to a mutation in a novel immune-associated nucleotide (Ian)-related gene. Genome Res 2002;12:1029-39.

106. Rutledge EA, Fuller JM, van Yserloo B, et al. Sequence variation and expression of the Gimap gene family in the BB rat. Exp Diabetes Res 2009;2009:835650.

107. Wallis RH, Wang K, Marandi L, et al. Type 1 diabetes in the BB rat: a polygenic disease. Diabetes 2009;58:1007-17.

108. Malaisse WJ, Courtois P, Scott FW. Insulin-dependent diabetes and gut dysfunction: the BB rat model. Horm Metab Res 2004;36:585-94.

109.Zhu W, Wu Y, Meng YF, et al. Association of obesity and risk of diabetic retinopathy in diabetes patients: a metaanalysis of prospective cohort studies. Medicine (Baltimore) 2018;97:e11807.

110. Tschöp M, Heiman ML. Rodent obesity models: an overview. Exp Clin Endocrinol Diabetes 2001;109:307-19.

111. Kinlen D, Cody D, O'Shea D. Complications of obesity. QJM 2018;111:437-43.

112. Chua SC Jr, Chung WK, Wu-Peng XS, et al. Phenotypes of mouse diabetes and rat fatty due to mutations in the $\mathrm{OB}$ (leptin) receptor. Science 1996;271:994-6.

113. Coleman DL. Obese and diabetes: two mutant genes causing diabetes-obesity syndromes in mice. Diabetologia 1978;14:141-8.

114. Caolo V, Roblain Q, Lecomte J, et al. Resistance to retinopathy development in obese, diabetic and hypertensive ZSF1 rats: an exciting model to identify protective genes. Sci Rep 2018;8:11922.

115. Chen H, Charlat O, Tartaglia LA, et al. Evidence that the diabetes gene encodes the leptin receptor: identification of a mutation in the leptin receptor gene in $\mathrm{db} / \mathrm{db}$ mice. Cell 1996;84:491-5.

116. Tang L, Zhang Y, Jiang Y, et al. Dietary wolfberry ameliorates retinal structure abnormalities in $\mathrm{db} / \mathrm{db}$ mice at the early stage of diabetes. Exp Biol Med (Maywood) 2011;236:1051-63.

117. Bogdanov P, Corraliza L, Villena JA, et al. The db/db mouse: a useful model for the study of diabetic retinal neurodegeneration. PLoS One 2014;9:e97302.

118. Kang MK, Park SH, Kim YH, et al. Dietary compound chrysin inhibits retinal neovascularization with abnormal capillaries in db/db mice. Nutrients 2016;8:782.

119. Belke DD, Larsen TS, Gibbs EM, et al. Altered metabolism causes cardiac dysfunction in perfused hearts from diabetic (db/db) mice. Am J Physiol Endocrinol Metab 2000;279:E1104-13.

120.Aasum E, Hafstad AD, Severson DL, et al. Age-dependent changes in metabolism, contractile function, and ischemic sensitivity in hearts from $\mathrm{db} / \mathrm{db}$ mice. Diabetes 2003;52:434-41.

121. Miyamura N, Bhutto IA, Amemiya T. Retinal capillary changes in Otsuka Long-Evans Tokushima fatty rats (spontaneously diabetic strain). Electron-microscopic study. Ophthalmic Res 1999;31:358-66.

122. Bhutto IA, Lu ZY, Takami Y, et al. Retinal and choroidal vasculature in rats with spontaneous diabetes type 2 treated with the angiotensin-converting enzyme inhibitor cilazapril: corrosion cast and electron-microscopic study. Ophthalmic Res 2002;34:220-31.

123. Ohashi K, Kim JH, Hara H, et al. WBN/Kob rats. A new spontaneously occurring model of chronic pancreatitis. Int J Pancreatol 1990;6:231-47.

124. Mori M, Fu X, Chen L, et al. Hereditary pancreatitis model WBN/Kob rat strain has a unique haplotype in the Pdwk1 region on chromosome 7. Exp Anim 2009;58:409-13.

125.Tsuji A, Nishikawa T, Mori M, et al. Quantitative trait locus analysis for chronic pancreatitis and diabetes mellitus in the WBN/Kob rat. Genomics 2001;74:365-9. 
126. Shinohara M, Masuyama T, Shoda T, et al. A new spontaneously diabetic non-obese Torii rat strain with severe ocular complications. Int J Exp Diabetes Res 2000;1:89-100.

127. Masuyama T, Fuse M, Yokoi N, et al. Genetic analysis for diabetes in a new rat model of nonobese type 2 diabetes, Spontaneously Diabetic Torii rat. Biochem Biophys Res Commun 2003;304:196-206.

128. Sasase T, Morinaga H, Abe T, et al. Protein kinase C beta inhibitor prevents diabetic peripheral neuropathy, but not histopathological abnormalities of retina in Spontaneously Diabetic Torii rat. Diabetes Obes Metab 2009;11:1084-7.

129. Fukuda M, Nakanishi Y, Fuse M, et al. Altered expression of aquaporins 1 and 4 coincides with neurodegenerative events in retinas of spontaneously diabetic Torii rats. Exp Eye Res 2010;90:17-25.

130. Kakehashi A, Saito Y, Mori K, et al. Characteristics of diabetic retinopathy in SDT rats. Diabetes Metab Res Rev 2006;22:455-61.

131. Matsuoka M, Ogata N, Minamino K, et al. Leukostasis and pigment epithelium-derived factor in rat models of diabetic retinopathy. Mol Vis 2007;13:1058-65.

132. Masuyama T, Katsuda Y, Shinohara M. A novel model of obesity-related diabetes: introgression of the Lepr(fa) allele of the Zucker fatty rat into nonobese Spontaneously Diabetic Torii (SDT) rats. Exp Anim 2005;54:13-20.

133. Goto Y, Suzuki K, Ono T, et al. Development of diabetes in the non-obese NIDDM rat (GK rat). Adv Exp Med Biol 1988;246:29-31.

134. Miyamoto K, Ogura Y, Nishiwaki H, et al. Evaluation of retinal microcirculatory alterations in the Goto-Kakizaki rat. A spontaneous model of non-insulin-dependent diabetes. Invest Ophthalmol Vis Sci 1996;37:898-905.

135.Liu T, Li H, Ding G, et al. Comparative genome of GK and Wister rats reveals genetic basis of type 2 diabetes. PLoS One 2015;10:e141859.

136.van Eeden PE, Tee LB, Lukehurst S, et al. Early vascular and neuronal changes in a VEGF transgenic mouse model of retinal neovascularization. Invest Ophthalmol Vis Sci 2006;47:4638-45.

137. Dollery CT, Bulpitt CJ, Kohner EM. Oxygen supply to the retina from the retinal and choroidal circulations at normal and increased arterial oxygen tensions. Invest Ophthalmol 1969;8:588-94.

138.Penn JS, Henry MM, Tolman BL. Exposure to alternating hypoxia and hyperoxia causes severe proliferative retinopathy in the newborn rat. Pediatr Res 1994;36:724-31.
139.Penn JS, Tolman BL, Lowery LA. Variable oxygen exposure causes preretinal neovascularization in the newborn rat. Invest Ophthalmol Vis Sci 1993;34:576-85.

140.Stahl A, Connor KM, Sapieha P, et al. The mouse retina as an angiogenesis model. Invest Ophthalmol Vis Sci 2010;51:2813-26.

141. Downie LE, Pianta MJ, Vingrys AJ, et al. Neuronal and glial cell changes are determined by retinal vascularization in retinopathy of prematurity. J Comp Neurol 2007;504:404-17.

142. Kern TS. Contributions of inflammatory processes to the development of the early stages of diabetic retinopathy. Exp Diabetes Res 2007;2007:95103.

143. Takahashi Y, Augustin W, Wyman M, et al. Quantitative analysis of retinal vessel changes in galactose-fed dogs. J Ocul Pharmacol 1993;9:257-69.

144. Niaz K, Maqbool F, Khan F, et al. Comparative occurrence of diabetes in canine, feline, and few wild animals and their association with pancreatic diseases and ketoacidosis with therapeutic approach. Vet World 2018;11:410-22.

145. Gardiner TA, Stitt AW, Anderson HR, et al. Selective loss of vascular smooth muscle cells in the retinal microcirculation of diabetic dogs. Br J Ophthalmol 1994;78:54-60.

146. Hatchell DL, Toth CA, Barden CA, et al. Diabetic retinopathy in a cat. Exp Eye Res 1995;60:591-3.

147. Mansour SZ, Hatchell DL, Chandler D, et al. Reduction of basement membrane thickening in diabetic cat retina by sulindac. Invest Ophthalmol Vis Sci 1990;31:457-63.

148. Linsenmeier RA, Braun RD, McRipley MA, et al. Retinal hypoxia in long-term diabetic cats. Invest Ophthalmol Vis Sci 1998;39:1647-57.

149. Reiser HJ, Whitworth UG Jr, Hatchell DL, Sutherland FS et al. Experimental diabetes in cats induced by partial pancreatectomy alone or combined with local injection of alloxan. Lab Anim Sci 1987;37:449-52.

150.Sanchez I, Martin R, Ussa F, et al. The parameters of the porcine eyeball. Graefes Arch Clin Exp Ophthalmol 2011;249:475-82.

151. King JL, Mason JO 3rd, Cartner SC, et al. The influence of alloxan-induced diabetes on Müller cell contractionpromoting activities in vitreous. Invest Ophthalmol Vis Sci 2011;52:7485-91.

152. Coughlin BA, Feenstra DJ, Mohr S. Müller cells and diabetic retinopathy. Vision Res 2017;139:93-100.

153. Umazume K, Barak Y, McDonald K, et al. Proliferative vitreoretinopathy in the Swine-a new model. Invest Ophthalmol Vis Sci 2012;53:4910-6. 
154. Yang Y, Hayden MR, Sowers S, et al. Retinal redox stress and remodeling in cardiometabolic syndrome and diabetes. Oxid Med Cell Longev 2010;3:392-403.

155. Umeyama K, Nakajima M, Yokoo T, et al. Diabetic phenotype of transgenic pigs introduced by dominantnegative mutant hepatocyte nuclear factor $1 \alpha$. J Diabetes Complications 2017;31:796-803.

156.Drago F, La Manna C, Emmi I, et al. Effects of sulfinpyrazone on retinal damage induced by experimental diabetes mellitus in rabbits. Pharmacol Res 1998;38:97-100.

157.Helfenstein T, Fonseca FA, Ihara SS, et al. Impaired glucose tolerance plus hyperlipidaemia induced by diet promotes retina microaneurysms in New Zealand rabbits. Int J Exp Pathol 2011;92:40-9.

158. Wong CG, Rich KA, Liaw LH, et al. Intravitreal VEGF and bFGF produce florid retinal neovascularization and hemorrhage in the rabbit. Curr Eye Res 2001;22:140-7.

159.Erb MH, Sioulis CE, Kuppermann BD, et al. Differential retinal angiogenic response to sustained intravitreal release of VEGF and bFGF in different pigmented rabbit breeds. Curr Eye Res 2002;24:245-52.

160. Ozaki H, Hayashi H, Vinores SA, et al. Intravitreal sustained release of VEGF causes retinal neovascularization

Cite this article as: Quiroz J, Yazdanyar A. Animal models of diabetic retinopathy. Ann Transl Med 2021;9(15):1272. doi: 10.21037/atm-20-6737 in rabbits and breakdown of the blood-retinal barrier in rabbits and primates. Exp Eye Res 1997;64:505-17.

161.Kim SY, Johnson MA, McLeod DS, et al. Retinopathy in monkeys with spontaneous type 2 diabetes. Invest Ophthalmol Vis Sci 2004;45:4543-53.

162.Jonasson O, Jones CW, Bauman A, et al. The pathophysiology of experimental insulin-deficient diabetes in the monkey. Implications for pancreatic transplantation. Ann Surg 1985;201:27-39.

163. Cao Z, Jensen LD, Rouhi P, et al. Hypoxia-induced retinopathy model in adult zebrafish. Nat Protoc 2010;5:1903-10.

164. Cao R, Jensen LD, Söll I, et al. Hypoxia-induced retinal angiogenesis in zebrafish as a model to study retinopathy. PLoS One 2008;3:e2748.

165.Delov V, Muth-Köhne E, Schäfers C, et al. Transgenic fluorescent zebrafish $\mathrm{Tg}$ (fli1:EGFP)y1 for the identification of vasotoxicity within the zFET. Aquat Toxicol 2014;150:189-200.

166. van Rooijen E, Voest EE, Logister I, et al. von HippelLindau tumor suppressor mutants faithfully model pathological hypoxia-driven angiogenesis and vascular retinopathies in zebrafish. Dis Model Mech 2010;3:343-53. 